\title{
CRITICAL REVIEW
}

\section{ETHNOGRAPHY OF HOPE IN EXTREME PLACES: AHRENDT'S AGORA IN CONTROVERSIAL TOURISM DESTINATIONS}

\author{
RAMI K. ISAAC AND VINCENT PLATENKAMP \\ Centre for Cross-cultural Understanding, NHTV Breda University of Applied Sciences, \\ Breda, The Netherlands
}

\begin{abstract}
In this critical review article, Isaac and Platenkamp present the case that tourism is not isolated from the world's dramatic situations in which humanity is at stake. Their argument principally centers on the devastating historical and contemporary conflict in Palestine and its relations with tourism. In this article, Isaac and Platenkamp maintain that (in relation to current happenings in Palestine) ethical and moral argumentation would be beside the point, and might even be a "cynical" exercise. They suggest that the conflict there is imbued with many kinds of normative argumentation. It is their view that positions need to be taken with regard to "Palestine," as in all extreme circumstances, where at the same time respect for the other positions becomes crucial. In this critical review article, therefore, Arendt's idea of "agora" will be introduced, in order to create a space where these "respectful positions" can be taken in a public arena and in order to contribute to a possible peaceful development. To Isaac and Platenkamp, tourism could enable this sort of "peaceful development" and could promote or help empower conditions where violence would be excluded, and where different sorts of "argumentation" could be generated and heard about these so-called "controversial spaces." In these respects, they maintain that tourism is a challenging field, because it has (itself) many faces - and they argue that such scenarios for "tourism" indeed could apply/should be applied for many controversial other spaces like Nepal and Burma (for instance) where (as in Palestine) the original population has no say in any economic development, such as that of tourism. But Isaac and Platenkamp recognize that (even in Burma) resistance against injustice can never be destroyed. Their own principal focus remains targeted upon Palestine, though. There, tourism is known to have "an incredibly high potential," despite the fact that (in their view) a strong and powerful "Israeli self" indeed controls the "humiliated Palestinian other." Thus, to our two reviewers in the Netherlands, therefore, tourism seems to be a communicative activity that might enable the implementation of Arendt's idea of and about "the agora." Isaac and Platenkamp suggest that there is no violence in the agora, itself, because only the force of argumentation rules . . . there. (Editor's Introduction)
\end{abstract}

Key words: Agora; Critical Theory; Pluralist normativity; Mode 3; Self-other; Tourism opportunities

Address correspondence to Rami K. Isaac, Ph.D., Centre for Cross-Cultural Understanding, NHTV Breda University of Applied Sciences, Mgr. Hopmanstraat 1:4817 JT Breda, The Netherlands. E-mail: Isaac.r@nhtv.nl 


\section{Introduction}

Critical Theory became a popular stream of thought during the 1930s in a Europe that stumbled into a world war. Since the 1930s Critical Theory also became more pessimistic about the possibilities of creating a more rational and happy society. The Frankfurt Institute and its relations tried to integrate psychoanalysis more into its theoretical background and did-in its American periodempirical studies on Nazism. "Dialectic of Enlightenment" by Horkheimer and Adorno (1947/1969) probably became the Institute's most important theoretical source of inspiration. It had been written during the Jewish genocide in the war, which probably has highly influenced its pessimism. After the Second World War the critical intention of the Critical Theory has been further developed by Habermas under the circumstances of a welfare state in Western Europe through his distinction between communicative and strategic action. The question is whether this distinction does also apply to other, more controversial, areas in the world than Western Late Capitalism.

In this critical review article, Critical Theory will be applied in the Middle East in more or less postmodern jacket. Starting point is the communicative action within life-worlds (Habermas, 1984) but without his search for consensus. Without Habermas' consensus theory of truth, though, relativism lurks at the corner of this critique. In order to go beyond such a relativist position Arendt's "agora" will be added. In the agora a pluralist discourse can be organized that fits well with the originally normative rationality of Habermas, but without its pressure to get to a consensus. This normative discourse will be elaborated as a mode 3 discourse (Kunneman, 2005; Platenkamp, 2007; Portegies, de Haan, \& Platenkamp, 2009), which is related to the earlier developed, academic mode 1 and professional, mode 2 discourses (Gibbons et al., 1994; Platenkamp, 2007; Tribe, 1997).

According to Gibbons et al. (1994), mode 2 knowledge emerges from "the context of application within its own distinct theoretical structures, research methods and modes of practice which may not be locatable on the prevailing disciplinary map" (p. 168). Mode 1 knowledge production remains associated with the more traditional disciplinary academic research, within university structures. Mode 3 knowledge production has been added to the other two modes because of the exclusion of normative and existential questions in this academic (mode 1) and professional (mode 2) research. In this review article, the central focus will be on mode 3 knowledge production. Mode 3 is connected to the slow questions that try to deal with sickness, death, repression, but also with moral virtues, as compassion, inner strengths, or wisdom and other sources of existential fulfillments that remain crucial for all generations in various places. With this theoretical framework an attempt will be made to structure the discussion in the Middle East, particularly in Palestine as in other controversial areas and to organize a much needed normative discourse in which the repressed voices of all parties involved will speak back in an egalitarian manner (Bhabha, 1994).

A peace conference was organized in Bethlehem in 2007, entitled "Building a Future Together: the Palestinian-Israeli Impasse," where different groups of Israel and Palestine and various international delegations were present. In this conference various stories were told from the perspectives of oppressed people in Israel and Palestine. The confrontational discussions took place in an atmosphere of openness, receptivity, and criticism. Based on this conference, the authors' idea emerged to relate Ahrendt's concept of agora to justice tourism. As can be concluded from the article of Isaac and Hodge (2011), on justice tourism, tourists felt connected to the situation in Palestine, in such a way that they became advocates of a just cause in their home countries. On the "agora" tourism could play a crucial role to enable this stimulating normative discourse.

\section{Critical Theory and Normative Rationality in its Postmodern Aftermath}

In many publications (Jay, 1973; Kolakovski, 1978) Critical Theory has been identified as a main stream of thought that came into existence in 1923 in Frankfurt, Germany. Right from the start there were many differences between its participants, although some crucial themes can be distinguished, also in tourism studies (Ateljevic, Pritchard, \& Morgan, 2008). Since the 1930 s Critical Theory 
reacted strongly against the analytical-empirical or positivistic tradition in social sciences, "traditionelle Theorie" as Horkeimer (1972) classified this tradition. The objective of this traditional theory was the formulation of general, internally consistent principles describing the positive facts of the world. General propositions were tested through verification or falsification; for Horkheimer the distinction between the two was not relevant. In traditional theory the goal always was pure knowledge, and certainly not action. "Kritische Theorie" for Horkheimer (1972) was a reaction to this theoretical concept. The goal was never pure knowledge, but knowledge as embedded in power relations and because of that oriented towards social actions. Value free science was criticized for the reason that it confirms the existing power relations by abstracting from them. Disinterested scientific research, in this sense, is impossible in a society that is in need of change. Researchers are part of society, and their analyses should be related to the changes of that society.

Since the 1960s Critical Theory has been under serious attack because of its perceived Marxist ideological bias. Its adherence based their ideological critique on traditional power relations on what they called universal values of emancipation. These values were related to the interest of oppressed groups starting with the labor class via the student movements, feminist, and other groups.

The critique of this position referred to the impossibility of the universal character of this critique. Instead of one group representing the universal resistance against oppression, a plurality of perspectives came into its place. Since then, these learning processes became a focal point of attention. In a self-reflexive approach of researchers, the critical intention that remained crucial in Critical Theory was related to a social scientific contribution to emancipation or the elimination of cruel and repressive practices. In normative discussions and its learning processes values are presented and confronted in a pluralized context where the "other always may be right" (Gadamer, 1990).

Habermas' distinction between communicative and strategic action distanciates him too from the Marxist way of thinking in the critical tradition. Much in line with this tradition his theoretical framework has been mostly used as a critique on late capitalism in Western societies. It remains obvious, though, that for example his "colonization of the life-worlds by strategic action" can easily be applied to the situation in the Middle East, as elsewhere. In the Middle East the coordination mechanisms of communicative action of Israelis and Palestinians are pushed aside by effective strategic action or economical and political power, but never completely. Within their life-worlds, people will always create their own realities, repressed or not. An example can be found in Cohen (2009), who describes the tensions in the French-Jewish immigrant to Israel, the main tension being between an adaptation of a French intellectual to Israel and an adaptation of the tsabar (son of the immigrant) to the international, Western intellectual community. No word is mentioned, here, about the tensions between Israel and Palestine and how Israel and the Israeli (immigrants) define themselves in their relations with the Palestinians. Did the author consider these tensions not important enough or is this discussion too risky? A place, an agora, therefore, is needed where people have guarantees to enable peaceful discussions from within their life-worlds.

\section{Hannah Arendt in the Public Space: The Agora}

Two "events" were characteristic during the life of Hannah Arendt for her own political position in the Middle East. During the 1930s Arendt escaped from Nazi Germany to Paris and from 1935 on she worked for the "Aliah des jeunes," an organization that helped the children from Jewish refugees to escape to Palestine. The other "Arendt event" had to do with the institution of the state of Israel in 1948. Arendt turned away from Zionism; she characterized this newly created state as a missed opportunity and plead for a multinational state in which Palestinians, Jews, and Arabs would be treated as equivalent civilians.

Through these public events Arendt implemented her own thoughts about political action in a convincing and truthful manner. As in the Greek "agora" free citizens, not bothered by daily necessities that are dealt with by their slaves, break out of their isolated positions by taking the initiative to participate through speech and action to the public discourse of the ancient city-state, where human plurality dictates the rules (Arendt, 1958, 1996) of their/communicative actions. In making this 
appearance in the public, political realm Arendt presents herself as a distinct person. She enters a web of human interrelationships - like in the Greek agora or in the Roman res publica - that supports the idea that men make their appearance in the human world by the disclosure of themselves as active agents in the reality in between people of this web. This world becomes human because through speech and acts the human animal succeeds in creating a world that exceeds the daily demands of biological survival and the fabricated world of the homo faber. This human world has no beginning nor ending, and because of its human plurality and the distinctive, equivalent positions people have in this world, it becomes a world, that is humanitarian in a necessary manner for men as a species. Without this world human life is threatened by "thoughtlessness," conformism, and the reduction of man as a whole to the level of a conditioned and behaving animal, by totalitarism (Arendt, 1958).

The two "events" are remarkable in another sense as well. Within the context of the web of interrelated relationships during the 1930s in Paris justice had a different meaning than in the context of 1948. Justice has and should have a universal meaning, although it has to be translated into different webs of relationships. The positions of Arendt in both contexts were related to justice as a universal concept. In the first context, however, she chose in favor of Zionism; in the second context she did the opposite. The reasons do not need much clarification, they become obvious within the subsequent contexts where justice remains a constant element of judgment. In the first context justice is related to the unspeakable position of the Jews during the 1930s in a hostile Europe; in the second context it shifts - for Hannah Arendt - to the injustice, done to the Palestinian (and Arab) people through the proclamation of the state of Israel. As consequence, about three quarters of a million Palestinians were forced to leave their homes and some 500 localities were destroyed by the Israeli military (Isaac \& Hodge, 2011).

The example of Hannah Arendt introduces the theme of this critical review article. There always is a tension between the universal width of a concept like justice and the different, also culturally defined contexts in which justice delivers a worthwhile contribution to the battle against injustice. The "right solution" is always open to a (universal) plural discourse in which many sides are disclosed from their isolated position and partake in a public discourse. People should be heard in this discourse from various, distinctive positions. A precondition, therefore, for this type of discourse must be human plurality. All relevant positions should be listened to and no one should be excluded in advance. In this light, the restoration of human plurality in areas where it has been pushed aside, like the Middle East, Burma, Nepal, Kashmir, or former Yugoslavia, seems to be a crucial point of attention. But this does not imply, as Isaac (2010a) has stipulated, that this discourse could not be stimulated in situations where this plurality does not exist. It "never altogether loses its potential character ... where words are not empty and deeds not brutal, where words are not used to veil intentions but to disclose realities, and deeds are not used to violate and destroy but to establish relations and create new realities" (Arendt, 1958, p. 200). In any situation humans want to be treated as humans and especially this discourse should be able to provide us in the most difficult circumstances with hope for a better future where plurality will play its important role in a more convincing manner.

Not only in extreme places, but more generally in professional and academic discourses, this type of position in most of the cases has been excluded. In this critical review article the authors' attempt is to revive this type of discourse and structure its contribution to the other, professional and academic, discourses through the distinction of a mode 1,2 , and 3 production of knowledge. The revival of this discourse will be pleaded for in the professional and academic tourism discourses in the Middle East as elsewhere.

\section{Mode 1, 2, and 3 in Controversial Areas}

From a historical (Western) perspective globally three phases can be distinguished in the production of (tourism) knowledge. First of all these three phases are based on the relations between academic, professional, and normative and more philosophical knowledge. These relations have changed in character from a predominance of religion, via a predominance of science to a more egalitarian relation between the three areas in this contemporary 
network society. These changes have direct consequences for the ways normative or existential issues, which are at stake in this critical review article, are to be discussed.

\section{Premodern Times}

In premodern times the basic epistemological and ontological assumptions in science and in professional disciplines were in essence grounded in religious and theological thought. Groups of students traveled around Europe to follow famous theological debates at mediaeval universities for example between nominalists and realists, which were understood as the highest events of knowledge production. In professions, like the medical ones, the diseases of our body as a microcosmos were interpreted as a reflection of the powers of the macro-cosmos, understood as religious and supranatural forces. The examples are abundant.

Religious and theological thinking was concentrated on understanding the supranatural and true essence of life and death as it has been written down in the Holy Book. All sciences and professional knowledge had to be in line with this central point from above (vertical transcendence) (Fig. 1). Normative discussions, too, were part of this same vertical transcendence.

\section{Modern Times: Positivism}

Modern times started with the Renaissance and became stronger during the rise of the new natural sciences in the 17 th century when the famous clashes between the new scientists and the religious authorities were symptomatic for a new period of knowledge production. Gradually religious belief was replaced by an enlightened belief in human's own rational capacities (Dijksterhuis, 1986). During the French revolution civilians danced around their altar of reason, science itself became a new belief at the end of the day that pushed the enchanted belief in supranatural powers aside. This new, positivist sway dominated Western thinking until the end of the last century, even afterwards. Normative and existential questions, the so-called "slow questions," were either pushed aside by scientific explanations or presented as trivial remnants of the past (Fig. 2). Science would solve all problems of human mankind, including those of life and death.

\section{Hybriditized Network Society}

Gibbons et al. (1994) discuss the transformation in knowledge production as a global phenomenon. Since the end of the 20th century and alongside "traditional" modes of knowledge production (mode 1 knowledge), a mode 2 knowledge has emerged created in a broader, transdisciplinary social and economic context of application (Fig. 3). It has been called mode 2 knowledge because the authors judged the conventional terms such as applied science, technological research or research development as inadequate. It is a new production of knowledge that has a strong influence on the dominating image of scientific knowledge that has always been interpreted as mode 1. An obvious example of mode 2 knowledge productions during the 1990 s has been a revolutionary contribution to

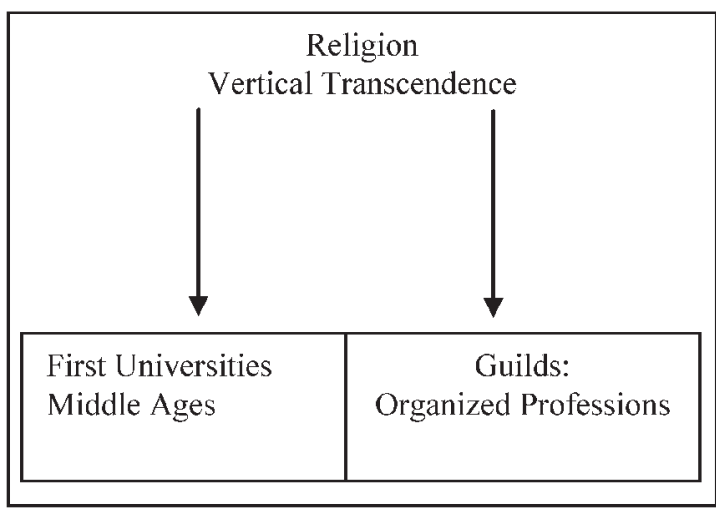

Vertical Transcendence

Figure 1. Premodern times. Source: Authors' own. 


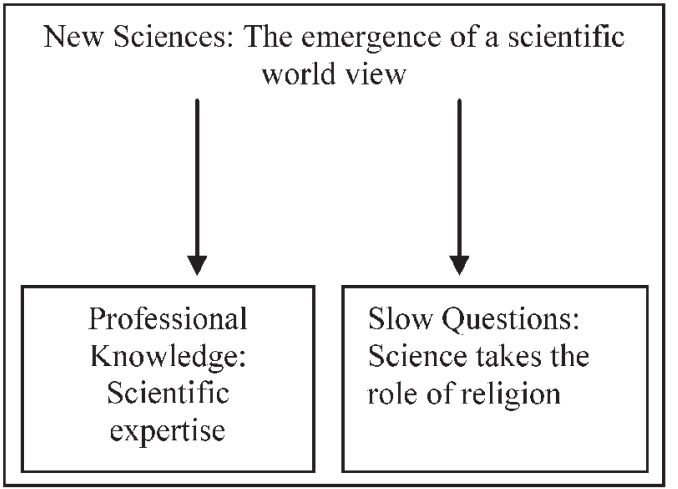

Figure 2. Modern times. Source: Authors' own.

the knowledge developments in the applied context of Information Communication \& Technology (ICT) by many stakeholders involved. Tribe (1997) and Portegies et al. (2009) used this distinction in the area of tourism studies. Coles, Hall, and Duval (2009) describe the distinction as follows: "Mode 1 appears to be the dominant type in higher education these days, as 'the traditional centre for knowledge production,' whereas mode 2 was originally anticipated as taking place outside university structures" (p. 84).

\section{Mode 3}

Mode 3 knowledge has been introduced by Kunneman (2005) in the awareness that during the second phase in both other modes there has been a long-term tendency to exclude the "slow questions," related to sickness, death, repression but also to moral virtues as compassion, inner strength, or wisdom and other sources of existential fulfillment that remain crucial for all generations in a variety of places. Kunneman calls inter alia for a relatively autonomous contribution of the treatment of these slow questions to professionalism in general. For example, in the reflections of tourism developers in Burma, moral questions that are related to injustice, human rights, and the everyday life of local people are excluded in their context of application. As a consequence, original villages have been destroyed, local people removed, and human rights violated for the sake of tourism development. Professionals who abstract from these circumstances do not consider this moral aspect, but focus only on the viability of tourism business.

There are two ways of tourism knowledge production connected in mode 2 in order to find adequate solutions for specific, context-related problems: on the one hand the objectifying knowledge of mode 1, and on the other hand the existentially and morally laden values that are co-determinant for organizing these solutions in mode 3. Knowledge production in mode 3 is related to the influential character of these values and frames of meaningful interpretations of the questions and problems in the contexts of application in mode 2 . In postindustrial societies there are sufficient available

Horizontal Transcendence

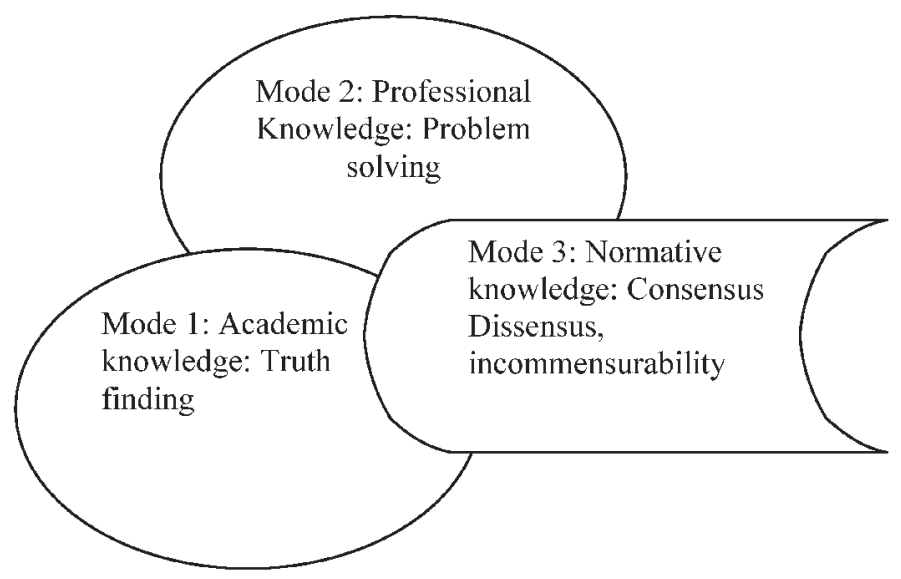

Figure 3. Hybriditized network society. Source: Authors' own. 
sources for the transformation of mode 1 knowledge into mode 2. This is not so much the case with mode 3. Economical and political power constellations (strategic action), but also dogmatically defended frames of interpretation, constitute obstacles to the necessary development of the learning processes in this mode. Therefore, it becomes the more important to stimulate a relative autonomous development of mode 3 that supports more adequate interventions in tourism professional practices. Characteristics for the argumentation structure for mode 3 is that consensus between positions can be, but does not need to be, reached. Dissensus is as possible as consensus and incommensurabilitythe logical disconnectedness of different positions - is a necessary condition in this mode.

In a hybriditized network society, consensus is not the necessary outcome of a discussion between various "transcendent" values and perspectives. This causes the difference with the communicative action as intended by Habermas (1984). Values need not be but can be incommensurable; they cannot be deduced from a common logical ground. One has to live with the differences, where there is no escape from them. In mode 3 discussions, these differences are included by understanding them through a plurality of perspectives.

The vertical transcendent of premodern times has, therefore, been replaced by a horizontal transcendent orientation in which there is no absolute last point, but openness, receptivity, and criticism. Consensus is possible but dissensus needs to be accepted as a fundamental possibility. In contrast to modern times where moral and existential questions were answered by rational explanations of sciences, but to the dissatisfaction of many, valueladen and existential discussions have been reintegrated into the academic and professional debates.

When hegemonic relations between Israel and Palestine still reign in their power relations, a mode 3 orientation introduces a necessary value-laden discussion on various topics that are produced because of these relations. These discussions have a more philosophical dimension because they are attached to the slow questions of life and death. Where the philosophical confrontation of positions may take place in mode 3 , the empirical investigation into the backgrounds of these positions, inspired as they are by mode 3 , takes place in mode
1 or 2. Looking back or speaking back only can take place in the evocation of a "third space" (Bhabha, 1994) beyond class, gender, race, and nationality. In mode 3 discussions communicative action becomes a "garden where the marginal can speak" from perspectives that include transcendent values and assumptions that create a plural discourse. Values are an important source of identification as well. Going to the by-pass roads (Selwyn, 2001) in Palestinian territory with a Palestinian guide from the Alternative Tourism Group (ATG) makes you a responsible traveler (Isaac, 2009, 2010a). At the same time the power relation of all these different markets with slow questions on poverty, frustrated wishes, and death might also cause a plurality of reactions from hosts and guests in the same transcendence that will be better off if it was open and horizontal. The ATG, established in 1995, is a Palestinian NGO specializing in tourism, which presents a critical look at the culture, history, and politics of Palestine and its complex relationship with Israel.

The Israeli-Palestinian conflict is imbued with normative and philosophical argumentation. Positions need to be taken here, and in particular respect for the other becomes crucial. In a human world where human plurality dictates the rules and people occupy distinctive, equivalent positions, Arendt's agora (1958) could contribute to a mode 3 discourse that supports the communicative action from within the life-worlds of Israeli and Palestinians. This communicative action, also in its postmodern jacket without consensus, is so much needed in order to contest the hegemony of strategic actions (Habermas, 1984) and its colonizing influences on the life-worlds of Palestine and Israel as in other situations where are the arguments of brutal power prevails.

\section{Israeli Self Versus Palestinian Other: Colonization of the Life-Worlds}

Palestine has been fragmented into three different sectors: Gaza, the West Bank, and Jerusalem. Due to the Israeli occupation, a viable tourism sector is becoming less and less likely. Despite all agreements with Israel, many areas of life are still under Israeli control. Israel controls all access to Palestine (land, air, and sea borders), most of the Palestinian water resourcesm and all movements of 
people and goods from, to and within Palestine (ATG, 2008). These facts have significant impacts on the development of tourism in Palestine and the dissemination of information to tourists. Jerusalem, the heart of tourism in the region, has been illegally annexed to Israel, filled with illegal settlements, besieged, surrounded by checkpoints, and encircled by the Separation Wall (Isaac, 2009; Isaac \& Ashworth, 2012), all of which has resulted in the city's isolation from its social and geographical surroundings (Isaac, 2010b).

\section{Mobility and Movement Restrictions as a Colonization of Local Life-Worlds}

In the West Bank, closure is implemented through an agglomeration of policies, practices, and physical impediments that have fragmented the territory into ever smaller and more disconnected cantons (World Bank, 2007). While physical impediments are the visible manifestations of closure, the means of curtailing Palestinian movement and access are actually far more complex and are based on a set of administrative practices and permit policies that limit the freedom of Palestinians to move home, obtain work, invest in business, expand or/and construct properties, and move about outside of their municipal jurisdiction. These administrative restrictions, rooted in military order associated with the Israeli occupation of the West Bank and the Gaza Strip, are used to restrict Palestinian access to large segments of the West Bank including all areas within the municipal boundaries of settlements, the "seam zone," the Jordan Valley, East Jerusalem, restricted roads, and other "closed" areas. Estimates of the total restricted areas are difficult to come by, but it appears to be in excess of $50 \%$ of the land of the West Bank (World Bank, 2007).

Since 1995 the Palestinians have been locked into 70 tiny enclaves comprising only $42 \%$ of the West Bank. They are encircled by more than 500 checkpoints and other obstacles to movement, and isolated from one another by the settlements, Israeli-only highways, and now the Separation Wall (Amnesty International, 1999, 2004; B'tselem, 2002; Halper, 2005).

According to Halper (2008) uses the term "Matrix of Control" to describe this state of affairs: this strategy was strikingly similar in concept to the East Asian gave of "Go." Unlike chess, where two opponents try to "defeat" each other by eliminating one another's pieces, the aim of "Go" is not actually defeat but rather to immobilize your opponent by taking control of key points on the game board, which is, indeed, a matrix. It was a strategy used effectively in Vietnam, where small forces of Viet Cong were able to pin down and virtually paralyze half a million American soldiers possessing overwhelming firepower. Israel's Matrix of Control accomplishes the same with the Palestinians. (p. 152)

The multiplication of controls and roadblocks, "flying" checkpoints within the Palestinian Territories have played a major role in this systematic policy for humiliation that has indeed gone beyond the requirement of "security" for the state of Israel (Moïsi, 2009).

\section{The Separation Wall}

The construction of the Wall began in June 2002. The Wall erases agricultural fields and houses within a massive 65 -yard swathe extending more than 450 miles - five times longer than the Berlin Wall. Thirty-eight villages and towns find themselves completely separated from their agricultural lands, unable to farm them. The parts of the Wall that are technically a see-through "fence" include sensors, trenches, security roads, mine fields, checkpoints, terminals, watchtowers, surveillance cameras, electronic sensory devices, and military patrols, certainly as dreadful a barrier to movement as any Wall. Some 50,000 Palestinians are trapped between the border and the Wall, facing alienation and impoverishment from their land and water, and ultimate transfer (United Nations, 2005). Defenders of the Wall note that $5 \%$ of it consists of solid concrete walls. This is accurate; however, they are 26 feet high - more than twice the height of the Berlin Wall - and they surround all the Palestinian cities, towns, and neighborhoods along their complicated route (Halper, 2008).

The Palestinian residents of East Jerusalem have been isolated from the wider West Bank society, 55,000 of them confined in neighborhoods completely encircled by the walls, forced to use slow, humiliating, and distant "terminals" to go to school, 
go to work, go shopping, or simply visit friends and relatives. On the other side of the Wall, more than 2 million Palestinians have been enclosed within the West Bank “cantons” (Halper, 2008).

As Carter (2002) states "The system of apartheid, with two people, occupying the same land, but completely separated from each other, with Israelis totally dominate and suppressing violence by depriving Palestinians of their basic human rights. This is the policy now being followed" (p. 215).

\section{Jerusalem}

Demography dictates all Israeli policy in Jerusalem as elsewhere. The priority in East Jerusalem (where some 220,000 Palestinians reside) at very minimum is to maintain the demographic balance existing in $1967 ; 28 \%$ Palestinians to $72 \%$ Jews. All governments' policies have been formulated with the following objectives. First, to assure a Jewish majority; secondly, to prevent contiguity between Palestinians of East Jerusalem and those in the West Bank; and finally, to reduce, at all costs, the number of Palestinians living in the city. To these ends, the Municipality of Jerusalem uses thousands of tricks (such as zoning plans), so that Palestinians are unable to make use of their land (ATG, 2008). It is indeed true what human rights organizations have long accused Israel of "judaizing" occupied East Jerusalem by making it impossible for Palestinians to get building permits in spite of a constant housing shortage. At the same time, the Jerusalem municipality has actively encouraged the illegal settlement of Israeli settlers in the area while carrying out a wave of home demolitions that have left hundreds of Palestinians homeless (Frykberg, 2011).

Recently, the Israeli Interior Ministry regulations provided for the abrogation of the rights of Palestinian residents of Jerusalem who move away from the city for a period of more than 7 years, whereas citizen of Israel can leave the country for any length of time, and their citizenship and all their rights are theirs in time without end (Frykberg. 2011).

A complex system involving the partisan use of planning and zoning mechanisms, land expropriation and house demolitions, combined with bureaucratic policies of revoking Palestinians' Jerusalem's residency for a myriad of reasons, ensures the "Jewish character" of the city. For example, in Jerusalem, Amir Cheshin, the Advisor on Arab Affairs for the Jerusalem Municipality under Teddy Kollek, for a time, under Ehud Olmert, states:

Israel turned urban planning into a tool of the government to be used to help prevent the expansion of the city's non-Jewish population. It was a ruthless policy, if only for the fact that the needs (to say nothing of the rights) of Palestinian residents were ignored. Israel saw the adoption of strict zoning plans as a way of limiting the number of new homes built in Arab neighbourhoods, and thereby ensuring that the Arab percentage of the city's population-28\% in 1967-did not grow beyond this level. Allowing "too many" new homes in Arab neighbourhood would mean 'too many' Arab residents in the city. The idea was to move as many Jews as possible into East Jerusalem, and move as many Arabs as possible out of the city entirely. Israeli housing policy in East Jerusalem was all about this numbers game. (Cheshin, Bill, \& Avi, 1999, pp. 31-32)

This is the policy now being followed.

Here too, the Israeli self obviously overrules the Palestinian other with - again - severe consequences for the life-worlds of all the people involved.

Tourism is a challenging field here, because it has many faces. In Palestine tourism is known to have an incredibly high potential, but a strong and powerful "Israeli self" controls the "humiliated Palestinian other." Humiliation is a strong sentiment in this regime as has been explained by Moïsi (2009). If hope is confidence, humiliation is impotence, an emotion that stems above all from the feeling that you are no longer in control of your life, either collectively, as a people, a nation, or individually as a single person. Humiliation and also inequality increase when you are convinced that the Other has interfered, or impose the private realm of your own life and made you totally dependent. Humiliation summarizes a sense of dispossession toward the present and even toward the future, a future in which your political, economic, and social conditions are dictated by the Other. An example of this humiliation is identified through the experience of people who live in a particular 
place; Palestinians living under the security regime of Israeli military control. In particular, by taking a view of the daily life of a society having to cross a military checkpoint we may better understand some of the processes and issues at stake in tangible and human terms. This inequality and humiliation reinforces the instinct of competition. It gives energy, sharpen and stimulate the appetite. But this presupposes the existence of a real window of hope. As Hammami (2004) stated, these inequality and humiliation at checkpoints and military controls, forces of survival and human agency under security regimes can only be comprehended as threats. However, they are not capable of destroying the resources of hope that could be galvanized in processes of restorative justice and ultimately in the unmaking of inequality (p. 1). More than this, the crossing of border through checkpoints creates a focal point for these resources of hope. The humiliating relation between the Israeli Self and the Palestinian Other has its tremendous effects on the daily life in Palestinian tourism. These effects encapsulate in this context that tourism became a political tool in the supremacy and domination of the Israeli establishment over land, and people (Isaac, 2010b; Selwyn, 1996, 2001, 2010) and an instrument for preventing the Palestinians from enjoying the benefits and the fruits of cultural and human interaction on which tourism thrives.

To recapitulate, the three (although there are many more) distinguished themes of this section all refer to the fact that a dominating Israeli self is colonizing the Palestinian life-worlds. There are systematic patterns of political repression that have invaded the everyday life of Palestinians and the Israeli in such as way that communicative coordination from within their life-worlds has been made impossible to an important degree. Of course, no one is controlled completely in their life-worlds. Therefore, the question here is what opportunities there are that may restore the necessary coordination mechanisms from within the Palestinian and the Israeli life-worlds. According to Habermas, these mechanisms are related to egalitarian communicative actions of groups of people who do not meet any serious power obstacle in their life-worlds discussions.
Communicative Action in the Agora Versus the Colonization of the Life-Worlds

Palestinians and Israeli life-worlds are being colonized by the strategic actions of the state of Israel. The checkpoints, scattered around the Palestinian landscape, are symbolic for the overwhelming control by Israel of the Palestinian lifeworlds. The systemic violence that colonizes these life-worlds reduces the perceived reality for all parties involved, also the Israeli. This goes for the analyses in mode 1 and 2, but more particularly it becomes painful in mode 3 . In their existential and normative reflections people should always be able to construct their basic points of view in a free and open dialogue. No reduction of what can be said should be possible in this arena. Through this dialogue in the spirit of a universal discourse (Habermas, 1984) hope can emerge at any time and at any place.

The crucial contribution of a normative discourse within the context of this conflict could be the respectful deconstruction of this powerful relation between an Israeli Self and a Palestinian Other. Departing from the humiliation of the Palestinians by the Israeli and their rightful claim to return to their "original homes" on the one hand, and the suffering of the Jews in the past and their concomitant, rightful claim for a territory on the other, one enters the "place of bother" as explained by Kunneman (2005). Sides have been taken according to the interpretations of many. It is only reasonably to say that Israelis themselves have encouraged the sense of humiliation in the Arab-Islamic world. By continuing to expand their settlements in the West Bank in spite of the promise made to Palestinians and to the international community, Israelis have illustrated their careless attitude towards the Palestinian sensitivity.

Tourism is one of the relevant activity in which these humiliations could be brought into perspective. Moïsi (2009) argues that both the US and Europe have been dominated by fears of the "Other" and of their loss of a national identity and purpose. Fear, the identity crises that confront the world, may be summarized by the concept of fear in the West. Instead of being united by their fears, the twin pillars of the West are more often divided 
by them - or rather, by bitter debates over how best to confront or transcend them. For Muslims and Arabs, the combination of historical grievances, exclusion from the economic boom of globalization and civil and religious conflicts extending from their homelands to the Arabic and Muslim diaspora has created a culture of humiliation that is quickly devolving into a culture of hatred. Meanwhile, Asia has been able to concentrate on building a better future and seizing the economic initiative from the American-dominated West and so creating a new culture of hope.

Thus, a much-needed platform could be developed via tourism activity in the Middle East in order to create this little bit of hope. Giddens (1991) introduces his "life politics," by which he meant the "individual attempt to reposition oneself culturally in the context of one's own life and in this way try to make a difference to ones immediate environment and also more broadly in the political realm" (Butcher, 2009, p. 251). And especially in the contemporary world of consumption there is a world of choice and freedom "where one can break free of traditional collective identities" (Butcher, 2009, p. 252). In this situation in Palestine, this world can generate changes in political terms in a way "discredited political institutions are unable to." Tourism, of course, is such a world. In extreme circumstances this idea might be a welcome way to apply tourism knowledge and skills in order to relate the industry to a normative discourse.

A tourism platform, where the morality of positions taken in policy, planning, development, and management are being interrogated, still is not the right concept. It suggests a meeting place where decisions are made. That is not the intention of this normative discourse combined with a tourism package. A better concept seems to be the "agora" or public space in an ancient Greek "polis" in the way Arendt (1958) refers to it. Tourists come here from all over the world to see the landmarks in the holy places of Palestine. A holiday really can become a "holy day" again if this agora, for example in the centre of Bethlehem, becomes a public space where free citizens from various places of the Middle East present themselves. The organization of such a public place would be a tourism opportunity. For example, the Alternative Tourism Group in Palestine could take the responsibility of organizing the "agora" because of the familiarity with groups of tourists that would be interested in this kind of activity. The content of the public discussions and themes could be related to a mode 3 type of normative and existential discourse in which people take sides with reference to the actual political situation. The agora could be situated in the Manger Square in Bethlehem, at the Peace Centre Building opposite to the Nativity Church. The agora is a free place where violence is forbidden and only words have value. Only those are welcome who respect the egalitarian positions that people hold.

It is a place that Habermas might call a room for communicative actions in the light of a universal discourse. Tourism can play an important role here, because it would enable people to escape from their daily routines and to participate in activities that matter during their "holy days." Tourists during their holiday in Palestine feel connected to the Palestinian-Israeli conflict and its normative obstacles. This time ethical tourism is not about smallscale projects in which morally enlightened and virtuous individuals can triumph in their isolated circles, opposed to mass tourism. Here, the political dimension is present in the whole project in such a manner that hope will never disappear and humiliation can be attacked through communicative actions instead of violence. At the same time, the cynical world of power and the colonization of lifeworlds turns on. But if tourism can contribute to create places of hope where people take sides without being frightened, it can make a difference in the public space, so cherished by Arendt.

\section{Conclusion}

In the tradition of the Critical Theory, normative rationality has been preserved, though in a Marxist context. In a postmodern context, a mode 3 discourse could replace this rationality in a more pluralist manner, so that differences in opinion can be confronted but also tolerated when consensus seems impossible. Arendt's agora perfectly suits this mode 3 discourse where sides are taken and the power of the argument counts instead of the argument of power. In the agora a polyphonic dialogue 
(Clifford, 1988) about normative and existential topics can be organized in places of bother like walled Bethlehem. No controversial issues are avoided in such a dialogue, but only with the power of the argument. The only alternative for power still seems to be language, dialogue, argumentation in mutual respect. Communicative action cannot be destroyed, but it can be stimulated. The agora seems to be a possible answer to this need of significant, meaningful communication.

In places of bother, originated by scars from the past, repressed voices of all parties involved can be awakened through communicative action. Through this communicative action organized in the "agora," repressed voices strengthen themselves against the all pervasive power and control of the political system and its systemic violence.

In Palestine, tourism is known to have an extraordinarily high potential, but a strong and powerful Israeli "self" controls the humiliated Palestinian "other." Therefore, tourism has been challenged in this critical review article as an activity that will enable the implementation of this normative discussion at the "agora."

As David Grossman says (cited in Cohen, 2009) "we have dozens of atomic bombs, tanks and planes. We confront people possessing none of these arms. And yet, in our minds, we remain victims. This inability to perceive ourselves in relation to others is our principle weaknesses" (p. 7).

One might argue that this normative discussion on the agora only makes sense when systemic violence has disappeared. However, this victimized perception, in fact, could change because of the new hope, created by a humanized, normative discourse. And hope is exactly what is needed to overcome daily humiliations that characterize relations between selves and others in terrorized areas. What goes for Palestine is valuable for any situation in the past, the present, or the future, where the opinions, convictions, and beliefs of people in their lifeworlds are terrorized, but never can and will be extinguished.

For tourism - and, in particular, for inquiry into open-to-the-future possibilities in tourism studies research - we maintain that attention should indeed be paid in controversial areas as to how tourism could in fact offer opportunities which decidedly create hope in situations of apparent "sustained/ longstanding despair." Such an orientation to tourism thus requires a rather different or fresh focusthat is, away from one where tourism is viewed only as an activity/site/place of relaxation and exotic pleasure. It is our view that tourism is inherently substantively embedded within society. Therefore, the tourism research community might also aim (should also aim?) to take sides in debates and discussions that reach well beyond held traditional discourse about the role and function of "tourism," itself. The agora-Arendt's agoraseems to be a relevant approach to enable this new aim in the tourism community, which we may also call the "moral" responsibility for advancing an agenda of critical research in controversial areas such as Palestine. This normative discourse could contribute essentially to a place in this controversial region, where the domination of violence is replaced by the force of argumentation. Justice tourism might be an attractive vehicle for this contribution.

\section{Glossary}

Agora: Ahrendt introduces the agora as a public space, comparable to the forum Romanum, which people present themselves as individuals with independent opinions. In this way, a pluralized discussion comes into being that creates the opportunity for individuals to present themselves as human beings and escape the thoughtlessness that dehumanizes our species.

Colonization of life-worlds: Normally speaking, actions of people in their life-worlds are coordinated by mutual communication. When this coordination mechanism is being replaced by the efficiency and affectivity of political or economic systems, this is called colonization of life-worlds.

Communicative action: Action based on communication that predominates in people's life-worlds.

Critical Theory: Theory as a function of social life, but defend at the same time the autonomy of theory. It means three things at least: 1) a historical perspective on developments and contradictions in society but at the same time an independent position towards any doctrine, including Marxism; 2) the insaneness (cf. Fromm, 1955) of society and the need for 
a radical change in the light of a struggle for emancipation; 3 ) the analysis of existing society itself is part of that society, which implies the need for self-reflection.

Incommensurability: Positions that cannot logical be compared

Mode 1: Traditional academic knowledge production.

Mode 2: It is a knowledge production outside the university structure in a context of application. Different stakeholders invest their interests in mostly project based research.

Mode 3: A relative autonomous area of philosophical, normative argumentation. In Critical Theory it has been dealt with through normative rationality. In a hybriditized network society, it needed an adaptation to the urge of upcoming relativism.

Normative rationality: Introduced by Critical Theorist as a second form of in addition to the instrumental rationality of the positivist tradition. Originally, it found its basis on the scientific truth claims of the Marxist historical analysis of the process of emancipation.

Strategic action: The coordination mechanisms by the efficient and effective power mechanisms of economy and politics that becomes independent of the communicative interaction of individuals.

\section{References}

Alternative Tourism Group. (2008). Palestine and Palestinians. Beitsahour: Author.

Adorno, Th. W. u.a. (1972). Der Positivismusstreit in der deutschen Soziologie. Darmstadt und Neuwied: Luchterhand Verlag

Amnesty International. (1999, December). Demolition and dispossession: The destruction of Palestinian Homes. London: Author.

Amnesty International. (2004, May). Under the rubble: House demolition and destruction of land and property. London: Author.

Arendt, H. (1958). The human condition. Chicago: The University of Chicago Press.

Arendt, H. (1996). The origins of totalitarianism. New York: Harcout, Brace and World.

Ateljevic, I., Pritchard, A., \& Morgan, N. (2008). The critical turn in tourism studies: Innovative research methodologies. Elsevier, Advances in Tourism Research Series.

Bhabha, H.K. (1994). The location of culture. London/New York: Routledge.

B'tselem. (2002, May). Land grab: Israel's settlements policy in the West Bank. Jerusalem: Author.
Butcher, J. (2009). Against ethical tourism. In J. Tribe (Ed.), Philosophical issues in tourism. Bristol, UK: Channel View Publications.

Carter, J. (2002). Palestine: Peace not apartheid. New York: Simon and Schuster.

Cheshin, A., Bill, H., \& Avi, M. (1999). Separate and unequal: The inside story of Israeli rule in East Jerusalem. Cambridge: Harvard University Press.

Clifford, J. (1988). The predicament of culture. Cambridge, MA: Harvard University Press.

Cohen, R. (2009, November 17). A Mideast truce. New York Times (Global Edition), p. 7.

Coles, C. Hall, C. M., \& Duval, D. T. (2009). Postdisciplinary tourism. In J. Tribe (Ed.), Philosophical issues in tourism (pp. 80-100). Bristol, UK: Channel View Publications.

Dijksterhuis E. (1986). The mechanization of the world picture: Phythagoras to Newton. Princeton: Princeton University Press.

Fromm, E. (1955). The sane society. New York: Rinehart $\&$ Co.

Frykberg, M. (2011). Legal experts warns of "ethnic cleansing" in Jerusalem. Retrieved from http://electronic intifada.net/content/legal-expert-warns-ethnic-cleansingjerusalem/9281

Gadamer, H. G. (1990). Wahrheit und Methode. Tübingen: Mohr.

Gibbons, M., Limoges, C., Nowotny, H., Schwartzman, S., Scott, P., \& Trow, M. (1994). The new production of knowledge. London: Sage.

Giddens, A. (1991). Modernity and self-identity. Self and society in the late modern age. Cambridge: Polity Press.

Habermas, J. (1984). The theory of communicative action. Cambridge: Polity Press.

Halper, J. (2005). Israel in a Middle East union: A two stage approach to the conflict. Tikkun, 2(1), 17-21.

Halper, J. (2008). An Israeli in Palestine: Resisting dispossession, redeeming Israel. London: Pluto.

Hammami, R. (2004). On the importance of thugs: The moral economy of a checkpoint. Middle East Report, 231, 26-34.

Horkheimer, M. (1972). Traditional and critical theory. New York: The Seabury Press.

Horkheimer, M., \& Adorno, T. W (1969). Dialektik der Aufklärung. Frankfurt am Main: Fischer Taschenbuch Verlag. (Original publication 1947)

Isaac, R. K. (2009). Can the Segregation Wall in Bethlehem be a tourist attraction? Tourism and Hospitality: Planning \& Development, 6(3), 247-254.

Isaac, R. K. (2010a). Alternative tourism: New forms of tourism in Bethlehem for the Palestinian tourism industry. Current Issues in Tourism, 13(1), 21-36.

Isaac, R. K. (2010b). Moving from pilgrimage to responsible tourism: the case of Palestine. Current Issues in Tourism, 13(6), 579-590.

Isaac, R. K., \& Ashworth, G. (2012). Moving from pilgrimage to dark tourism: Leveraging tourism in Palestine. Tourism, Culture \& Communication, 11(3), 149-164. 
Isaac, R. K., \& Hodge, D. (2011). An exploratory study: Justice tourism in controversial areas. The case of Palestine. Tourism Planning \& Development, 8(1), 101-108.

Jay, M. (1973). The dialectical imagination. Boston/ Toronto: Little Brown and Company.

Kolakovski, L. (1978). Main currents of Marxism. Its origins, growth and dissolution. Oxford: Oxford University Press

Kunneman, H. (2005). Voorbij het dikke-ik Amsterdam: B.V. Uitgeverij SWP.

Moïsi, D. (2009). The geopolitics of emotion: How cultures of fears, humiliation and hope reshaping the world. New York: Doubleday.

Platenkamp, V. (2007). Contexts in tourism and leisure studies. A cross-cultural contribution to the production of knowledge. Wageningen: Wageningen University.

Portegies, A., de Haan, T., \& Platenkamp, V. (2009). Knowledge production in tourism. The evaluation of contextual learning processes in destination studies. Tourism Analysis, 4, 523-536.
Selwyn, T. (1996). The tourist image: Myths and myth making in tourism. Chichester, UK: Wiley.

Selwyn, T. (2001). Landscapes of separation: Reflections on the symbolism of by-pass roads in Palestine. In B. Bender \& M. Winter (Eds.), Contested landscapes: Movements, exile and place. Oxford: Berg.

Selwyn, T. (2010). Ghettoizing matriarch and a city: An everyday story from the Palestinian/Israeli borderlands. Journal of Borderlands Studies, 24(3), 39-55.

Tribe, J. (1997). The indiscipline of tourism. Annals of Tourism Research, 24(3), 638-657.

United Nations. (2005). The humanitarian impact of the West Bank Barrier on Palestinian communities. Jerusalem: OCHA.

World Bank. (2007). Report on movement and access restrictions in the West Bank: Uncertainty and inefficiency in the Palestinian economy. Paris: World Bank Technical Team. 